\title{
Post-Election Coalition-Building in a Comparative Politics Classroom
}

\author{
Adam E. Howe \\ Fairfield University
}

Working Paper

\begin{abstract}
Embedded in a unit on legislative institutions in an Introduction to Comparative politics course, students work through the process of post-election coalition-building, a frequent occurrence in parliamentary democracies. The activity is based on politics in the UK and operates under the following conditions: an election has been held and no clear winning party has emerged. In order to avoid a vote of no confidence, or the dissolution of the legislature, workable governing coalitions must be formed. Students have an entire class session (1 hour 15 minutes) to form coalitions that will be cohesive enough to withstand pressures from competing elites and the public. The purpose of this activity is to enhance student understanding of parliamentary electoral systems while also gaining a more detailed understanding of parties and institutional rules in parliamentary democracies. Most importantly, this simulation strives to foster student understanding of the complexities inherent to strategic bargaining, thus demonstrating how both formal and informal institutions structure the behavior of elites. The normative goal is to have students gain a greater appreciation for the complexity of political decision-making without resorting to easy cynicism over the perceived failures of "do nothing politicians".
\end{abstract}




\section{Introduction}

The following paper investigates and evaluates the value of coalition-building exercises as a pedagogical tool in comparative politics courses. At the heart of this project, is a desire to more effectively gauge short-term and long-term student learning outcomes. The first pertains to comprehension of course material and integration of prior classroom learning into the coalitionbuilding exercise. The second set of goals is based on retention and the development of transferable skills, which are useful both inside and outside the classroom setting. As a way of proceeding, this article first examines the rationale for simulation learning based on an examination of similar exercises conducted in undergraduate political science classrooms. The second half of this piece discusses the specific parliamentary coalition-building activity conducted in my Introduction to Comparative Politics course, while also investigating future areas for project development.

Why Classroom Simulations?

For new faculty, the very thought of conducting a classroom simulation evokes nervousness from instructors and students alike. In the first case, instructors are often concerned that designing and implementing a simulation will be too time-consuming or detract unnecessarily from the importance of teaching scheduled course material. Students may be apprehensive about engaging in a new activity with peers, particularly if evaluation for the assignment is of the high-stakes variety.

In introductory courses, especially, it is common for faculty and students to expect a wide variety of content delivered in a traditional format. For many students, even though passive learning might not serve their long-term scholarly interests, there is comfort in familiarity. For 
more reserved students a lecture-based course may be appealing, as participation might not be a core consideration for end of semester assessment. This is not to say that traditional lectures aren't without pedagogical value. Inevitably, instructors must find the most efficient ways to ensure that students are absorbing class content. In order to apply theory to cases, students must first learn theory. Since many of the concepts and theories in politics courses are far from selfevident, there are good reasons for using lectures to build foundational knowledge.

Instead of nurturing a false dichotomy between active learning through simulations and traditional lectures, the structure of the course should determine the proper place for each teaching strategy. While certain theories are more amenable to games and simulations, the inherent risk is that students leave the course thinking that one theory has far greater explanatory power than others. Thus, it is important to spread class activities out across the semester to ensure that student learning remains unbiased.

As a form of active learning, simulations are particularly important in introductory or "gateway" courses. Based on the voluminous literature on this subject, Archer and Miller argue that active learning promotes core teaching values such as critical thinking and content retention (Archer and Miller 2011, 430). It also may have a secondary role in attracting new students to the political science major as students tend to enroll in courses where active learning components are incorporated (Ibid, 431). The latter point is worth considering for faculty at small colleges and universities where growing the major is prioritized.

Depending on the effectiveness of the pre-simulation design and their actual incorporation into the course, simulations are thought to enhance student motivation (Raymond and Usherwood 2013, 5). Furthermore, there is evidence that students who engage in simulations may actually perform better on multiple choice exams (Ibid, 11). In the context of an American 
Government course, Frederking demonstrates that students scored higher on 6 of 8 learning objectives after engaging in classroom simulations (Frederking 2005). However, the actual relationship between simulations and student performance on associated learning objectives is complex and likely influenced by a host of other intervening variables.

At their core, all simulations are intended to serve as an active-learning strategy in the classroom. The growing interest in active learning makes sense given changing student expectations and classroom dynamics. In an era where technology-based distractions are the rule rather than the exception, it is increasingly difficult for students (and faculty!) to lecture for the duration of a fifty-minute class session. It is far too tempting for students to tune out and turn their attention toward smartphones and laptops. While some may object that students need to take greater responsibility for their own learning, it is also true that student behavior both consciously and unconsciously is structured by the learning environment itself.

Passive learning often reproduces traditional power imbalances that do not necessarily serve the interests of either the student or instructor. In lecture-based courses, the overwhelming tendency for students is to defer to the instructor on most matters, reducing many students to the role of spectator. Also, class activities and simulations require students to apply learning, while still retaining the prospect of asking an instructor or teaching assistant for additional guidance. Finally- and perhaps this is the most overlooked point- student activities and simulations serve as a form of socialization. Through group problem-solving, students build community and group communication skills, thus more closely modeling post-college life.

Within the comparative politics classroom, several teaching strategies exist for conveying knowledge of important theories and concepts. As certain theories lend themselves more readily to games and simulations (particularly rational choice approaches), sections of comparative 
politics courses focused on elite decision-making or the study of civil wars and revolutions are ripe for exercises on the prisoner's dilemma or the collective action problem. In the Prisoner's Dilemma, where students are asked to demonstrate the problem of cooperation in an environment of imperfect information. Typically, this exercise requires students to volunteer, as the prisoner's dilemma example works best with two-three students. The idea of the collective action problem often works well as a whole class activity. Here, students must weigh the costs of maximizing individual benefits without absorbing all the costs of defection. While employed frequently, this type of simulation requires the instructor to carefully weigh incentive structures-not only to make the activity work- but also to align with the points allocation scheme set out in the syllabus.

\section{Coalition-Building in the Classroom}

Coalition-building activities work well because they tend to be content-driven, whereas without proper prompting and debriefing the collective action problem and prisoner's dilemma may still feel abstract to students. Depending on the course, and instructor expectations, coalition-building activities can range from a simple group exercise in rational problem-solving to a fully interactive classroom, where students immerse themselves in inter-elite bargaining.

One of the most structured examples of coalition-building can be found in Shellman's (2011) mock German election and coalition-building exercise. Here students work through every part of the political process from campaigns, to elections, to post-election cabinet formation. Furthermore, Shellman asks students to write their own position papers, thus demonstrating that they can articulate respective party platforms. Marsh and Bucy, in their simulation of Russian federalism, also require students to conduct research on their districts and roles as representatives in the Russian Duma (Marsh and Bucy 2002). This has the added advantage of making students 
agents in their own learning. However, simulations need not require in-depth country knowledge to meet instructor goals.

In a more general variant, Kaarbo and Lantis demonstrate how with proper preparation, students can form workable political coalitions in the fictitious kingdom of Oceania (Kaarbo and Lantis 1997). Like the stimulation used in my comparative politics course- though not entirely fictitious-students are provided with materials on the country in advance and are have party platforms in hand. The advantage of using this method is that it provides the instructor with greater leverage to customize the simulation in order to emphasize specific learning goals. In this sense, the number of votes cast, or party platforms can be changed to suit new political developments. With fictitious countries the instructor has even more power to change the rules of the game to accommodate learning outcomes.

There are tradeoffs involved in assigning students to work through actual country-cases vs. fictitious variations. In terms of the general learning outcomes associated with coalitionbuilding exercises, namely, those of working cooperatively toward a single goal, understanding the role of multiple parties in a single political system, and recognizing the effects of structural constraints on elite political decision-making, simulations which make use of fictitious countries can be highly effective. One of the potential limitations is ensuring that knowledge transfers from the activity to other parts of the course. In other words, how much country-based knowledge is important? While this depends entirely on desired learning outcomes, in the context of a case study, it likely makes more sense to directly link the simulation to the country under consideration. If the main objective is to teach the complexity inherent to elite political bargaining, whether the country under analysis is real or fictious matters less. 
In my classroom, and as modeled through other online versions, I have typically relied on the UK example, as a means of demonstrating compromise in a multi-party system. My rationale- though fine examples exist for other countries- is that the UK provides a small enough set of parties, where students in one class session can absorb enough information about party platforms to form reasonable coalitions. For instance, with only an introductory knowledge of the UK political system, students through a process of elimination can determine that given their platform the Scottish National Party (SNP), is unlikely to form a winning coalition with the Conservative Party (Tories). Likewise, there is no reason to suspect that the Labour Party would work alongside the Irish Democratic Unionist party.

Secondly, as most students in my courses were raised in the United States, and thus socialized into this political system, the notion of first-past-the-post electoral rules make intuitive sense. In an introductory course, there is the additional challenge of working within a system that features a wide variety of competitive parties. In this respect, it may be too frustrating for students to work through all of the possible coalition permutations. As a teaching tool, if students are able to form coalitions too easily, then they fail to appreciate the complexity of elite-level politics.

Finally, this type of coalition-building exercise likely works best in the context of stable democratic systems. The main reason is that in deeply divided societies, the prospects of creating durable coalitions which cross-cut ethnic or religious groups may either instill a false sense of optimism or pessimism among students (i.e. "Look how easy it is to form a coalition" or “There's no way these parties could ever compromise"). While it is normatively appealing for Sunni and Shi'a parties in Iraq to build workable political coalitions, this is very difficult to 
simulate in a classroom setting. Secondly, in these systems, violence is often seen as a means of bargaining, which again is not amenable to the learning goals in this sort of simulation.

\section{Simulation Background}

The coalition-building simulation builds upon other similar initiatives undertaken in comparative politics and international relations courses. It is also modeled after several election simulations designed for a non-specialist audience $(\mathrm{CNN})^{1}$. Prior to engaging in any simulation, students in my classes work through a unit on legislative institutions in presidential and parliamentary systems. Therefore, students enter the simulation with a functional knowledge of the possibility and likelihood of post-election coalition-building in parliamentary democracies. Similarly, they develop a greater awareness of how elites are often constrained in their choices by peers and their constituents alike. Finally, students recognize that party discipline tends to be higher in parliamentary systems, therefore the structural obstacles to crafting workable coalitions become evident. Furthermore, in the American classroom, students often enter with a basic intrinsic familiarity of presidential systems, and occasionally make the assumption that the same logic inherent in the presidential executive and legislative system maps onto their parliamentary counterparts. Thus, the simulation also makes students aware of how they may not have the same tools presidents have in shaping politics.

\section{The Activity}

This activity is designed for a single 1 hour 15 minute class session, though depending on class size it could be executed over the course of several classes. Students are first provided with

\footnotetext{
${ }^{1}$ The CNN Activity served as an important point of departure for this activity. While the CNN version asks participants to move parties into a coalition by clicking on potential combinations, it does not permit students to make intentional choices about potential coalitions. In other words, one could simply click their way into a coalition without in-depth knowledge of political parties or the stakes of cooperation.
} 
a list of parties and some of their basic characteristics (Liberal, conservative, regional etc). For a shorter classroom activity, more information can be presented at the start. In the allotted time, students are encouraged to conduct their own research on each party. Thus, through our course management system, they are able to access the official website for each party to get in-depth party platform information. For the second half of the activity, students are provided with hypothetical election results. Hypothetical, because in recent UK history close elections have been the exception rather than the norm. Ahead of the class session, I have prepared a list of possible working coalitions, based only on party ideology and the number of seats won in Parliament. Students work within a group setting to form a governing coalition with the tacit reminder that dissolving parliament and calling for new elections is not an option for this activity. After roughly 30-40 minutes, we reconvene as a class and each group calls out their coalition while also providing a justification for why it might work in practice. As there are typically 4-5 theoretically workable coalitions, it is rare for one group to have discovered all possible permutations.

As an observer, students view this project as a sort of puzzle and often become highly competitive in order to crack the code of workable political coalitions. Thus far I have encountered few situations where students are not engaged in conversation throughout the allotted activity period.

\section{Preliminary Outcomes and Limitations}

While students have informally expressed their enthusiasm regarding this activity, I have not yet had a large enough sample size to effectively gauge student learning outside of their performance on quizzes and exams (which are likely influenced by a whole set of other variables). In future iterations, I plan on designing a pre and post-test (worth participation 
points), whereby I can more accurately gauge student learning. In most cases, students do correctly identify workable coalitions and provide cogent responses for why certain parties may want to work together. I have also used this simulation in classes with no more than 25 students. Through work in small groups, I can closely monitor the types of questions and/or the direction of conversation. In larger class settings, teaching assistants can also play an active role in monitoring group discussion.

One of the major limitations to this work is accurately modeling the results of a fictional election. However, many of the questions that arise from students are also valuable. For instance, how might Brexit and political polarization in Britain change negotiation and bargaining strategies? As no perfect political coalitions exist, what are some of the costs of cooperation, particularly for hardliners in party constituencies?

Though this activity is done in a small group setting, assigning parties to groups and having them engage with peers in political bargaining may serve as an appealing alternative. However, this also rests on the assumption that students have a more advanced knowledge of party politics in Britain, which would require additional instructor preparation and likely multiple class sessions. For example, students would have the added burden of figuring out the degree to which multiple political issues were amenable to compromise. This is a difficult tradeoff in introductory courses where instructor anxiety about content delivery typically runs high.

The goal of this simulation is not to substitute or eliminate other forms of learning in a country-case study unit. I have found that a certain amount of traditional lecture is necessary as a means of ensuring that students possess enough background knowledge on the country to fully participate in the activity. In class video clips and reading quizzes can serve as additional 
teaching tools to ensure that students are well-prepared for other types of assessment throughout the semester.

At the conclusion, it is important to also consider the ethical implications of coalitionbuilding exercises in an era where far-right nationalist parties are gaining traction around the globe. In modeling cabinet formations, we must be sensitive to this reality without pretending as if this phenomenon doesn't exist. However, it is important to inquire whether role-playing activities in parliamentary democracies should incorporate fringe parties. In the UK case, this is less of a concern as the Brexit party received zero seats in the latest elections, and its predecessor the UK Independence Party never won enough seats to make for even a hypothetical coalition partner. Yet, this is less true in Germany where the far-right AFD has a strong regional presence. What is to be done in cases like Poland or Austria where nationalist parties wield executive power? Here, the instructor is faced with important ethical questions. Is it appropriate to have students adopt the party platform of a far-right party, even in the context of a simulation? How does one avoid the temptation to equivocate and inadvertently legitimize parties with a xenophobic agenda? Finally, what are the costs of only choosing non-controversial country cases for coalition-building simulations? While there are no simple answers to these questions, the issue of case-selection and instructor preparation for class activities has perhaps never been more important. 


\section{Work Cited}

Archer CC and MK Miller: 2011. "Prioritizing Active Learning: An Exploration of Gateway Courses in Political Science”. PS: Political Science and Politics 44(2) 429-434.

Frederking, B. 2005. "Simulations and Student Learning." Journal of Political Science Education 1(3), 385-393.

Greene, R, S. Mankarious and N. Garcha. "Could You Govern the U.K.?” CNN. Accessed 1/15/20 at <https:/www.cnn.com/2015/05/01/world/uk-election-british-governmentcoalition-builder/index.html>

Kaarbo and Lantis. 1997. "Coalition Theory in Praxis: A Comparative Politics Simulation of the Cabinet Formation Process". PS: Political Science and Politics 30(3) 501-506.

Raymond C. and S. Usherwood. 2013. "Assessment in Simulations”. Journal of Political Science Education 9(2) 157-167.

Shellman, SM. 2001. “Active Learning in Comparative Politics: A Mock German Election and Coalition-Formation Simulation”. PS: Political Science and Politics 34(4) 827-834. 
Appendix: Coalition-Building Activity

Assignment Background:

In this activity, you are required to form a parliamentary coalition based upon hypothetical elections in the UK. Based upon each party's stated policy platforms, you will quickly learn that certain coalitions are possible, while others are not. In order to form a stable majority, your coalition must have at least 323 seats to avoid a vote of no confidence. To form your coalition, please consult the attached party platforms and Blackboard for links to individual political party websites.

*Please note that you are not permitted to form a minority government or dissolve parliament.

Hypothetical Election Results (seats gained)

Labor Party: 273

Conservative Party: 273

SNP (Scottish National Party): 52

Liberal Democrats: 27

UKIP (UK Independence Party): 3

DUP (Democratic Unionist Party): 9
PC (Plaid Cymru):3

Green (Green Party): 1 
Basic Party Platforms:

1. Conservative (Tory)

Economics: Free market, government privatization

Politics: Unionist, Opposes Irish, Scottish, Welsh independence, Pro-Brexit

\section{Labour:}

Economics: Democratic Socialist, trade-unionist, focus on greater economic/social equality

Politics: Pro European Union, historically the largest opposition party when Tories are in power.

\section{Scottish National Party:}

Economics: Democratic Socialist, trade-unionist

Politics: Pro-Scottish independence, emphasizes environmental issues.

\section{Liberal Democrats:}

Economics: Free market w/some government regulation, pro EU integration

Politics: Moderate, traditionally occupies a middle ground between Conservatives and Labor 


\section{UKIP (Brexit Party):}

Economics: Economic nationalism, Pro-Brexit, skeptical of European Union

Politics: Far Right, Unionist, does not support regional parties.

\section{Democratic Unionist Party:}

Economics: Economic nationalism, skeptical of European Union and unfettered free markets.

Politics: Conservative, Unionist, opposes reunification of Ireland

\section{Social Democratic and Labor Party:}

Economics: Democratic Socialist, Pro-European Union

Politics: Supports reunification of Ireland.

\section{Plaid Cymru:}

Economics: Democratic Socialist, Pro-European Union

Politics: Supports Welsh independence

\section{Green Party:}

Economics: Democratic Socialist, focuses on environmentally sustainable development Politics: Pro-European Union, Globalist 